\title{
AVALIAÇÃO DO VIGOR DE SEMENTES DE ALFACE NUAS E PELETIZADAS ${ }^{1}$
}

\author{
SIMONE MEDIANEIRA FRANZIN² ${ }^{2}$, NILSON LEMOS DE MENEZES ${ }^{3}$, DANTON CAMACHO GARCIA ${ }^{3}$ \\ TERESINHA ROVERS ${ }^{4}$
}

\begin{abstract}
RESUMO - As sementes de alface são de tamanho pequeno, pouca massa e formato irregular, por isso a peletização é a forma utilizada para facilitar sua distribuição e manuseio. Embora a técnica seja conhecida há muitos anos, pouco se estudou sobre os métodos para avaliação da qualidade fisiológica das sementes, após este tratamento. O objetivo do trabalho foi comparar a eficiência de alguns testes para avaliar o vigor em sementes nuas e peletizadas de alface. Utilizaram-se seis lotes de sementes nuas e peletizadas de alface das cultivares Regina e Vera, nos quais se aplicaram os testes de germinação, primeira contagem, envelhecimento acelerado, solução osmótica e índice de velocidade de germinação. $\mathrm{O}$ delineamento experimental utilizado foi inteiramente casualizado, com quatro repetições, realizando-se comparação de médias pelo teste de Tukey a 5\% de probabilidade de erro. As sementes peletizadas apresentaram menor vigor do que as sementes nuas. Os testes de envelhecimento acelerado, solução osmótica (-0,25 MPa) e o índice de velocidade de germinação foram eficientes para estratificar lotes de sementes nuas de alface, quanto ao vigor, sendo recomendados, também, para uso em sementes peletizadas. Entretanto, a peletização pode exercer influência nos resultados, necessitando adaptações na metodologia para utilização na comparação entre sementes nuas e peletizadas.
\end{abstract}

Termos para indexação: Lactuca sativa, qualidade fisiológica, péletes, testes de vigor

\section{ASSESSMENT OF VIGOR IN SIMPLE AND PELLETIZED LETTUCE SEEDS}

\begin{abstract}
Lettuce seeds are small with little mass and irregular shape and thus pelletization is the form used to facilitate their distribution and handling. Although the technique has been known for many years, little has been studied on the methods for assessing seed physiological quality after this treatment. The objective of this study was to compare the efficiency of some tests in assessing the vigor in loose and pelletized lettuce seeds. Six batches of loose and pelletized seeds of the Regina and Vera cultivars were used and the germination, first counting, accelerated aging, osmotic solution and germination speed index tests were applied. A completely randomized block design was used with four replications and the means were compared by the Tukey test at $5 \%$ probability. The pelletized seeds presented less vigor than the loose seeds. The accelerated aging, osmotic solution $(-0.25 \mathrm{MPa})$ and the germination speed index were efficient in stratifying loose lettuce seed batches for vigor and are also recommended for use on pelletized seeds. However, pelletization can influence the results, requiring adaptations to the methodology for use in comparison among loose and pelletized seeds.
\end{abstract}

Index Terms: Lactuca sativa, physiological quality, pellets, vigor tests

\footnotetext{
${ }^{1}$ Submetido em 16/12/2003. Aceito para publicação em 11/08/2004. Parte da Dissertação de Mestrado do primeiro autor, apresentada a UFSM.

${ }^{2}$ Doutoranda do Programa de Pós-Graduação em Agronomia, Depto de Fitotecnia, CCR, UFSM- RS (smfranzin@yahoo.com.br).
}

${ }^{3}$ Prof. Dr. Programa de Pós-Graduação em Agronomia, Depto de Fitotecnia, CCR, UFSM- RS

${ }^{4}$ Doutoranda do Programa de Pós-Graduação em Agronomia, Depto De Fitotecnia, CCR, UFSM- RS (smfranzin@yahoo.com.br). 


\section{INTRODUÇÃO}

A crescente modernização na produção de hortaliças, assim como a utilização de sementes pequenas e de alto custo, com desperdícios na semeadura e no descarte de mudas, recomendam o uso de técnicas como a peletização de sementes.

A peletização consiste no revestimento das sementes com sucessivas camadas de material seco e inerte, dando a elas formato arredondado, maior massa e acabamento liso, o que facilita sua distribuição e manuseio, especialmente àquelas muito pequenas, pilosas, rugosas ou deformadas (Silva et al., 2002).

As sementes peletizadas apresentam como vantagens a semeadura mais precisa, menor estresse com o desbaste, uso de menor quantidade de sementes e facilidades no manuseio (Roos \& Moore, 1975). Soma-se a isto, a possibilidade de utilização de nutrientes, fitorreguladores de crescimento, inseticidas, fungicidas, entre outros elementos que são incluídos no processo de peletização, facilitando o desenvolvimento e o estabelecimento das plântulas. No entanto, o pélete pode afetar o desempenho das sementes durante a germinação e, a superação das dificuldades impostas por este, está intimamente relacionada ao vigor das sementes. Conseqüentemente, pequenas diferenças de vigor contribuem para a desuniformidade da população inicial das plântulas, havendo, no entanto, após a superação desta dificuldade, igualdade na velocidade de crescimento, formando mudas uniformes (Silva \& Nakagawa, 1998).

A qualidade fisiológica das sementes é avaliada rotineiramente pelo teste de germinação, entretanto, este resultado nem sempre corresponde com a emergência em campo (Bhering et al., 2000). Como forma de complementar as informações obtidas pelo teste de germinação são utilizados os testes de vigor, que irão avaliar o potencial de emergência das sementes e o rápido desenvolvimento de plântulas normais sob ampla diversidade de condições de ambiente (AOSA, 1983).

Para sementes peletizadas, embora os estudos tenham tido início há bastante tempo, não existe consenso entre os pesquisadores sobre os métodos de avaliação da qualidade fisiológica e, se os testes utilizados para sementes nuas também apresentam sensibilidade para avaliação destas sementes.

Estudos realizados por Silva \& Nascimento (2002) em sementes de alface relatam que existe influência dos materiais usados na peletização sobre a germinação das sementes, bem como na velocidade com que estas germinam. Ainda com relação ao assunto, Zink (1954) também verificou que ocorre maior percentagem e maior velocidade de germinação nas sementes nuas em relação às sementes peletizadas. Contudo, nos testes de vigor realizados em laboratório, Coraspe et al. (1993) observaram que não há diferenças significativas entre sementes nuas e peletizadas.

De acordo Bertagnolli (2001), sementes nuas de alface apresentam maior velocidade de emissão de raiz primária do que sementes peletizadas, porém as primeiras são mais afetadas por temperaturas elevadas e baixa disponibilidade hídrica, enquanto as peletizadas apresentam maior resistência a essas condições adversas.

O desempenho das sementes peletizadas após o tratamento, segundo Franzin \& Menezes (2002), pode ser atribuído a vários fatores além da peletização, dentre eles a qualidade das sementes, as diferentes condições dos estudos e, principalmente, a composição dos péletes.

Assim, em razão da discordância entre os resultados encontrados para o vigor das sementes peletizadas de alface, faz-se necessário, mais estudos para comparar a aplicação de testes de vigor em sementes de alface nuas e peletizadas.

O objetivo do presente trabalho foi comparar a eficiência de testes de vigor em sementes de alface nuas e peletizadas.

\section{MATERIAL E MÉTODOS}

O experimento foi realizado no Laboratório Didático e de Pesquisas em Sementes (LDPS), do Departamento de Fitotecnia, na Universidade Federal de Santa Maria, Santa Maria/RS.

Amostras de $100 \mathrm{~g}$ de sementes de três lotes de sementes de alface nuas de cada cultivar (Regina e Vera) foram enviados para a empresa INCOTEC América do Sul - tecnologia em sementes, para serem peletizadas. Metade do conteúdo das sementes da amostra enviada, entretanto, permaneceu sem peletização, isto é, nuas e foram mantidas em câmara fria com temperatura de $\pm 5{ }^{\circ} \mathrm{C}$ e $45 \%$ de umidade relativa do ar até a montagem do experimento.

Os testes relacionados a seguir foram utilizados para avaliar a qualidade fisiológica das sementes.

Teste de germinação (G) - realizado com quatro repetições de 100 sementes, semeadas em caixas plásticas do tipo gerbox, sobre três folhas de papel filtro, umedecidas com água destilada na proporção de 2,5 vezes o peso do papel substrato. As sementes foram mantidas à temperatura constante de $20^{\circ} \mathrm{C}$. As contagens foram realizadas aos quatro e sete dias, conforme Brasil (1992), considerando-se como germinadas as plântulas normais de cada repetição, obtendo- 
se, assim a média das repetições, com os dados expressos em percentagem de germinação.

Primeira contagem (PC) - realizada conjuntamente com o teste de germinação, computando-se os dados obtidos no quarto dia após a instalação do teste, através da percentagem de plântulas normais, com comprimento igual ou superior a 2 $\mathrm{cm}$. Considerou-se como resultado do teste a média das repetições, expressa em percentagem de plântulas normais.

Envelhecimento acelerado (EA) - utilizou-se de cada lote de sementes, quantidade suficiente para distribuição uniforme das sementes sobre uma tela de alumínio fixada no interior de caixas plástica tipo gerbox, funcionando como compartimento individual (mini-câmara). No interior dessas mini-câmaras foram adicionados $40 \mathrm{~mL}$ de água destilada e, em seguida, as caixas gerbox foram transferidas para um germinador regulado a $41^{\circ} \mathrm{C}$, onde permaneceram por um período de 72 horas. Após esse período, quatro repetições de 100 sementes foram submetidas ao teste de germinação, computando-se a percentagem de plântulas normais por repetição.

Solução osmótica (SO) - o teste foi conduzido com quatro repetições de 100 sementes, que foram semeadas em caixas plásticas do tipo gerbox, sobre três folhas de papel filtro umedecidas com solução osmótica de -0,25 MPa. As concentrações foram obtidas com polietileno glicol 6000 (PEG 6000), de acordo com Villela et al. (1991). Utilizou-se durante o teste a temperatura de $20^{\circ} \mathrm{C}$ e o período de avaliação estendeu-se por sete dias, observando-se a percentagem de plântulas normais por repetição.

Índice de velocidade de germinação - o teste foi realizado no substrato sobre papel, em caixas plásticas do tipo gerbox, com quatro repetições de 100 sementes. Para cada repetição, foi calculado o índice de velocidade de germinação (IVG), somando-se o número de sementes germinadas a cada dia, dividido pelo respectivo número de dias transcorridos a partir de semeadura, conforme Maguire (1962).

Análise estatística - o delineamento experimental utilizado foi o inteiramente casualizado, com quatro repetições e a análise estatística realizada através da comparação de médias pelo teste de Tukey a 5\% de probabilidade de erro. As variáveis de germinação e suas derivações usadas foram transformadas em $\operatorname{arcsen}(\mathrm{x} / 100)^{1 / 2}$, utilizando-se o Sistema de Análise Estatística para Microcomputadores - SANEST (Zonta et al., 1986). A comparação das médias foi efetuada pelo teste de Tukey, também em nível de $5 \%$ de probabilidade de erro.

\section{RESULTADOS E DISCUSSÃO}

Na Tabela 1 encontram-se os dados obtidos nos testes de germinação e vigor para sementes nuas e peletizadas de alface cultivar Regina. Observa-se que houve estratificação dos lotes na germinação e no vigor, com diferenças significativas entre lotes de sementes nuas e peletizadas. Esses resultados não podem ser atribuídos a qualidade inicial das sementes, visto que o mesmo lote deu origem aos dois tipos de sementes, nuas e peletizadas. Sendo assim, atribuiu-se esses resultados às influências da peletização e/ou dos métodos utilizados para avaliar estas sementes.

Nos resultados do teste de germinação observou-se diferenças significativas entre os lotes de sementes nuas, onde os lotes 1 e 2 foram superiores ao lote 3. Para as sementes peletizadas, houve redução significativa da percentagem de germinação somente para o lote 1 , quando comparadas às sementes nuas e o lote 2 foi superior aos demais quando as sementes foram peletizadas. Assim, verifica-se que a peletização afetou negativamente a germinação das sementes do lote1, provavelmente, pela dificuldade de absorção de água e oxigênio imposta pelo material constituinte do pélete. Também, verificou-se que as condições indicadas para o teste de germinação de sementes nuas de alface, freqüentemente, não servem para as peletizadas, as quais germinam melhor em temperaturas menores do que $20^{\circ} \mathrm{C}$ (Franzin \& Menezes, 2002), onde ocorre melhor difusão de oxigênio. Os resultados observados corroboram aqueles encontrados por Zink (1954) e Franzin \& Menezes (2002) onde as maiores percentagens de germinação ocorreram nas sementes nuas.

No teste de primeira contagem (Tabela 1), nota-se que não houve diferenças significativas entre os lotes para sementes nuas. Para sementes peletizadas houve redução acentuada no percentual das plântulas normais para os lotes 1 e 3 . O lote 2 sofreu menor redução no vigor após a peletização, mostrandose superior aos demais depois do tratamento, conforme verificado no teste de germinação. As diferenças encontradas neste teste, também, podem ser atribuídas aos mesmos fatores que afetaram a germinação, que provavelmente determinaram menor velocidade de absorção de água e oxigênio pelas sementes de alface peletizadas.

Pelos resultados do teste de envelhecimento acelerado (Tabela 1), observa-se baixo percentual de plântulas normais, com exceção do lote 2 para sementes nuas. Embora o estresse imposto pelo teste tenha sido drástico, principalmente para as sementes peletizadas, foi possível a estratificação dos lotes, 
TABELA 1. Comparação de médias de germinação (G-\%), primeira contagem da germinação (PC-\%), envelhecimento acelerado (EA-\%), solução osmótica -0,25 MPa (SO-\%) e índice de velocidade de germinação (IVG) de sementes nuas e peletizadas de alface, cv. Regina. Santa Maria - RS, 2002.

\begin{tabular}{clllcr}
\hline Lotes & G & PC & EA & SO (-0,25 MPa) & IVG \\
\hline L1N & $97 a^{*}$ & $93 a$ & $46 \mathrm{~b}$ & $56 \mathrm{~cd}$ & $8 \mathrm{a}$ \\
L2N & $90 \mathrm{ab}$ & $94 \mathrm{a}$ & $89 \mathrm{a}$ & $94 \mathrm{a}$ & $10 \mathrm{a}$ \\
L3N & $78 \mathrm{c}$ & $89 \mathrm{ab}$ & $30 \mathrm{c}$ & $90 \mathrm{ab}$ & $4 \mathrm{~b}$ \\
L1P & $75 \mathrm{c}$ & $44 \mathrm{c}$ & $16 \mathrm{~d}$ & $27 \mathrm{e}$ & $3 \mathrm{~b}$ \\
L2P & $89 \mathrm{~b}$ & $80 \mathrm{~b}$ & $52 \mathrm{~b}$ & $43 \mathrm{de}$ & $7 \mathrm{a}$ \\
L3P & $76 \mathrm{c}$ & $57 \mathrm{c}$ & $30 \mathrm{c}$ & $75 \mathrm{bc}$ & $3 \mathrm{~b}$ \\
\hline CV $(\%)$ & 6,4 & 5,8 & 13,8 & 11,4 & 15,5 \\
\hline
\end{tabular}

* Médias seguidas pela mesma letra na coluna, não diferem entre si pelo teste de Tukey a $5 \%$ de probabilidade de erro.

$\mathrm{N}=$ sementes nuas $\quad \mathrm{P}=$ sementes peletizadas

confirmando a superioridade do lote 2 . Vale ressaltar que houve redução do vigor pelo teste de envelhecimento, das sementes peletizadas em relação às sementes nuas, com exceção do lote 3 que não diferiu estatisticamente, embora seja o lote de menor vigor. $\mathrm{O}$ teste de envelhecimento acelerado, no entanto, ao ser utilizado por Coraspe et al. (1993), na avaliação da qualidade de sementes peletizadas de alface cultivar Verônica, não mostrou diferenças significativas entre sementes nuas e peletizadas, mesmo quando houve indicação de maior percentagem de germinação para as sementes nuas.

A mesma tendência foi observada no teste de solução osmótica, utilizando-se o potencial de $-0,25 \mathrm{MPa}$, onde o lote 2 apresentou o melhor desempenho entre as sementes nuas, sem entretanto, diferir do lote 3 . O teste também estratificou os lotes de sementes peletizadas, porém mostrou o lote 3 como o mais vigoroso, diferindo dos demais testes. Provavelmente, as condições utilizadas neste teste não foram as mais adequadas para as sementes peletizadas.

Pelos resultados do IVG das sementes da cultivar Regina (Tabela 1), considerou-se que as sementes nuas germinaram mais rapidamente do que as peletizadas, no entanto, só foram observadas diferenças estatísticas no lote 1. Esses resultados são corroborados por aqueles descritos por Zink (1954), onde as sementes nuas apresentaram maior velocidade de germinação que as peletizadas. De acordo com Silva \& Nascimento (2002), as sementes nuas apresentam maior velocidade de germinação em laboratório, mas não diferirem entre si em casa de vegetação. A diferença observada entre os tipos de sementes do lote 1 sugere que houve efeito da
TABELA 2. Comparação de médias de germinação (G-\%), primeira contagem da germinação (PC-\%), envelhecimento acelerado (EA-\%), solução osmótica -0,25 MPa (SO-\%) e índice de velocidade de germinação (IVG) de sementes nuas e peletizadas de alface, cv. Vera. Santa Maria - RS, 2002

\begin{tabular}{clllcc}
\hline Lotes & G & PC & EA & SO $(-0,25 \mathrm{MPa})$ & IVG \\
\hline L1N & $81 \mathrm{a}^{*}$ & $76 \mathrm{ab}$ & $31 \mathrm{bc}$ & $49 \mathrm{bc}$ & $4 \mathrm{~b}$ \\
L2N & $92 \mathrm{a}$ & $88 \mathrm{a}$ & $45 \mathrm{a}$ & $81 \mathrm{ab}$ & $4 \mathrm{~b}$ \\
L3N & $91 \mathrm{a}$ & $73 \mathrm{ab}$ & $46 \mathrm{a}$ & $87 \mathrm{a}$ & $9 \mathrm{a}$ \\
L1P & $54 \mathrm{~b}$ & $43 \mathrm{~b}$ & $12 \mathrm{~d}$ & $12 \mathrm{~d}$ & $7 \mathrm{~b}$ \\
L2P & $85 \mathrm{a}$ & $82 \mathrm{ab}$ & $27 \mathrm{c}$ & $32 \mathrm{c}$ & $3 \mathrm{~b}$ \\
L3P & $87 \mathrm{a}$ & $81 \mathrm{ab}$ & $44 \mathrm{ab}$ & $62 \mathrm{ab}$ & $3 \mathrm{~b}$ \\
\hline CV $(\%)$ & 6,8 & 20,1 & 11,0 & 22,6 & 18,5 \\
\hline
\end{tabular}

* Médias seguidas pela mesma letra na coluna, não diferem entre si pelo teste de Tukey a $5 \%$ de probabilidade de erro.

$\mathrm{N}=$ sementes nuas $\quad \mathrm{P}=$ sementes peletizadas

peletização e das condições do teste sobre os resultados.

Na Tabela 2 encontram-se os resultados de germinação e vigor obtidos para os lotes de sementes nuas e peletizadas da cultivar Vera.

No teste de germinação não houve diferenças significativas entre os lotes de sementes nuas. No entanto, quando comparadas com aquelas peletizadas, somente o lote 1 mostrou redução significativa da germinação, atribuída a esse tratamento. Os outros dois lotes, não diferiram significativamente da germinação das sementes nuas. Esses resultados sugerem que as condições do teste ainda podem ser aprimoradas para os dois tipos de sementes, a fim de expressar com maior precisão a qualidade das sementes.

Pelos resultados provenientes do teste de envelhecimento acelerado, nota-se que o teste foi bastante drástico para as sementes, conforme verificado para cultivar Regina, porém foi capaz de detectar diferenças entre os lotes de ambos tipos de sementes. O lote 3 foi o único que não apresentou redução do vigor com o revestimento, porém entre as sementes nuas, não diferiu do lote 2 . O lote 1 mostrou menor vigor nos dois tipos de sementes e teve a maior redução no vigor após a peletização. Esses resultados confirmam observações de vários autores (Spinola et al., 1998; Bhering et al., 2000; Franzin \& Menezes, 2002), que relatam que o teste de envelhecimento acelerado é um teste adequado para aplicação em sementes de hortaliças.

O teste de solução osmótica, também promoveu estratificação entre os lotes de sementes nuas e peletizadas. As sementes do lote 3 , tanto as nuas quanto a peletizadas, 
apresentaram maior vigor e, as do lote 1 , mostraram menor vigor, como já havia sido verificado no teste de envelhecimento acelerado.

O índice de velocidade de germinação não foi eficiente quanto os outros teste para avaliar o vigor das sementes desta cultivar. A velocidade de emergência (IVG) das sementes peletizadas foi a mesma e, somente as sementes nuas do lote 3 apresentaram germinação mais rápida que todas as demais.

Os resultados referentes ao vigor e à germinação mostraram diferenças entre sementes nuas e peletizadas, mesmo que os lotes tenham sido formados a partir do mesmo lote inicial. Isto indica, que o tratamento de peletização ou as características de cada teste utilizado podem dificultar a avaliação do vigor das sementes de alface. Assim, acredita-se ser necessários outros estudos sobre os testes de vigor em sementes peletizadas, com diferentes fontes de recobrimento, antes de padronizar os testes recomendáveis às sementes de alface.

\section{CONCLUSÕES}

Os testes de envelhecimento acelerado, solução osmótica (-0,25 MPa) e índice de velocidade de germinação são eficientes para estratificar lotes de sementes nuas de alface, em função do vigor, sendo os dois primeiros, também, indicados para uso em sementes peletizadas.

Os mesmos testes, no entanto, necessitam adaptações em suas metodologias para que possam ser utilizados na comparação entre os dois tipos de sementes.

\section{AGRADECIMENTOS}

INCOTEC América do Sul - tecnologia em sementes

\section{REFERÊNCIAS}

ASSOCIATION OF OFFICIAL SEED ANALYSIS. Seed vigor testing handbook. East Lasing: AOSA, 1983. 88p. (Contribution, 32).
BERTAGNOLLI, C.M. Desempenho de sementes nuas e peletizadas de alface submetidas ao estresse hídrico e térmico e formação de mudas em cultivo hidropônico. 2001. 48f. Dissertação (Mestrado em Produção vegetal) - Universidade Federal de Santa Maria, Santa Maria, 2001.

BHERING, M.C.; DIAS, D.C.F.S.; GOMES, J.M.; BARROS, D.I. Métodos para avaliação do vigor de sementes de pepino. Revista Brasileira de Sementes, Brasília, v.22, n.2, p.171-175, 2000.

BRASIL. Ministério da Agricultura e Reforma Agrária. Regras para análise de sementes. Brasília: SNDA/DNDV/CLAV, 1992. $365 \mathrm{p}$.

CORASPE, H.M.; IDIARTE, H.G.; MINAMI, K. Avaliação do efeito da peletização sobre o vigor de sementes de alface (Lactuca sativa, L.). Scientia Agricola, Piracicaba, v. 50, n.3, p.349-354, 1993.

FRANZIN, S.M.; MENEZES, N.L. Análise de Sementes. 2 temperaturas e qualidade de água para a germinação de sementes peletizadas de alface. Informe Técnico, Santa Maria, n.1, 2002. 4p. (CCR - UFSM).

MAGUIRE. J.D. Speed of germination-aid in selection and evaluation for seedling emergence and vigour. Crop Science, Madison, v. 2, n.1, p. 176-177, 1962.

ROOS, E.E.; MOORE, F.D. Effect of seeds coating on performance of lettuce seeds in greenhouse soil tests. Journal of the American Society for Horticultural Science, Alexandria, v.100, n.5, p.573$576,1975$.

SILVA, J.B.; NAKAGAWA, J. Confecção e avaliação de péletes de sementes de alface. Horticultura Brasileira, Brasília, v.16, n.2, p. 151-158, 1998.

SILVA, J.B.C.; SANTOS, P.E.C; NASCIMENTO, W.M. Desempenho de sementes peletizadas de alface em função do material cimentante e da temperatura de secagem dos péletes. Horticultura Brasileira, Brasília, v.20, n.1, p. 67-70, p. 335-341, 2002.

SPINOLA, M.C.M.; CALIARI, M.F.; MARTINS, L; TESSAROLI NETO, J. Comparação entre métodos para avaliação do vigor de sementes de cenoura. Revista Brasileira de Sementes, Brasília, v. 20, n. 2, p. 301-395, 1998.

VILLELA, F.A.; DONI FILHO, L.; SEQUEIRA, E.L. Tabela de potencial osmótico em função da concentração de polietileno glicol 6000 e da temperatura. Pesquisa Agropecuária Brasileira, Brasília, v.26, n.11/12, p. 1957-1968, 1991.

ZINK, F.W. Studies with pelleted lettuce seed.American Society for Horticultural Science, Davis, n.15, p. 335-341, 1954.

ZONTA, E.P.; SILVEIRA, P.S.; ALMEIDA, A. Sistema de análise estatística para microcomputadores - SANEST. Pelotas: UFPel, Instituto de Física e Matemática, 1986. 150p. 